\title{
El síndrome cálido-fresco en la medicina popular criolla del Chaco argentino
}

\author{
GUSTAVO F. SCARPA \\ Instituto de Botánica "Darwinion" \\ CONICET. San Isidro. Argentina
}

\section{RESUMEN}

En base a entrevistas semiestructuradas, realizadas con criollos del Chaco argentino, se describe la categorización de elementos de la farmacopea vegetal, animal y mineral según el síndrome cálido-fresco, así como las etiologías de sus enfermedades-trastornos. Según esto, se identifican modelos etiológico-terapéuticos en su medicina popular, caracterizados como alopáticos y homeopáticos, para 428 aplicaciones medicinales de su farmacopea. Se analiza además la articulación de lo cálido-fresco con otros sistemas simbólicos presentes en su medicina y con las cualidades sensibles de los remedios. El síndrome cálido-fresco constituye el criterio etiológico-terapéutico central de la medicina popular criolla.

Palabras clave: Cálido-fresco, Síndrome, Chaco, Medicina, Criollos, Argentina.

\section{SUMMARY}

On the basis of semi-structured interviews with criollos of the Argentinian Chaco, the author describes the categorization of plant, mineral and animal elements of their pharmacopoeia according to the hot-cold syndrome, as well as the etiologies of their illnesses and diseases. He identifies the etiologico-therapeutic models of their medicine, which are characterized as allopathic and homeopathic and have 428 applications. In addition, he analyzes the articulation of the hot-cold principle with other symbolic systems and with the sensitive properties of the remedies. The hot-cold syndrome is the main etiologico-therapeutic criterion of the folk medicine of these Creoles.

Key words: Hot-cold, Syndrome, Chaco, Medicine, Criollos, Argentina.

\section{INTRODUCCIÓN}

Las categorías de "cálido" y "fresco", aplicadas a plantas medicinales, alimentos, etiologías de enfermedades y a criterios terapéuticos, han sido suficientemente documentadas en numerosas sociedades mestizas latinoa-

RDTP, LIX, 2 (2004): 5-29 
mericanas (Foster 1953, 1994; Queiroz 1984; Currier 1966, Peeters 1979; Messer 1987, entre otros). Según Foster (1979), la investigación en Latinoamérica reportada en más de 100 fuentes ha revelado que la dicotomía frío-caliente está difundida ampliamente y constituye la unidad etiológica más importante de la medicina tradicional o popular. En dichos trabajos se discute frecuentemente su relación con la teoría humoral grecopersa-árabe, especialmente en lo que atañe a la participación del principio de oposición hipocrático en la medicina folk.

Como es sabido, para la antigua teoría hipocrática lo cálido y lo fresco, junto con lo seco y húmedo, representaban categorías valorativas de los humores corporales - sangre, bilis negra, bilis amarilla y flema-, cuyo desequilibrio en el cuerpo humano originaba la enfermedad. La teoría humoral, refigurada por la cultura cristiana y el galenismo, estuvo en boga en España hasta los siglos XVI y xVII desde donde habría ingresado a Hispanoamérica. Aquí sólo habrían perdurado los conceptos de cálido-fresco -incorporando respectivamente lo seco y lo húmedo- para caracterizar trastornos y remedios (Foster 1953).

Trabajos que tratan con cierta profundidad el síndrome de referencia en sociedades campesinas de Argentina son los de Jiménez de Pupareli (1984), y García y Jiménez (1986) para las provincias de Corrientes y Entre Ríos, los de Idoyaga Molina (1999a, 1999b) para la provincia de San Juan, y los de Idoyaga Molina (1999c, 2000) e Hilgert (2001) para el Noroeste andino. Para el Chaco argentino constituyen antecedentes importantes para este trabajo los estudios de Sturzenegger $(1985,1989,1999)$ con campesinos de Las Lomitas y los de Scarpa (2000b, 2002, 2004) para los criollos aquí tratados. Sturzenegger (1999) dedica un capítulo de su libro a tratar el tema en una sociedad criolla muy cercana a la nuestra, tanto en términos socioculturales, espaciales como de hábitat, aunque con mayor presencia de elementos culturales de raigambre hispano-guaraní. Uno de los rasgos comunes de estos trabajos es la ausencia de un relevamiento exhaustivo de la farmacopea vegetal y animal relacionada con el síndrome, así como la falta de descripciones detalladas de las aplicaciones medicinales específicas - a excepción de los trabajos de Hilgert (2001) y Scarpa (2004)_. Estas deficiencias sesgan de antemano los resultados acerca de los niveles de participación de lo cálido y lo fresco en la medicina popular, así como la dilucidación de los modelos etiológico-terapéuticos involucrados.

Los criollos del oeste de Formosa -especialmente las mujeres-, muestran un vivo interés con respecto al tratamiento y características de sus enfermedades, así como en la puesta en práctica y difusión de los remedios de su farmacopea. En efecto, un análisis pormenorizado del tema 
(Scarpa 2004) evidencia el empleo de 163 especies vegetales en un total de 621 aplicaciones medicinales, para el tratamiento de 95 tipos de afecciones $^{1}$. El discurso criollo sobre enfermedades y remedios se halla frecuentemente penetrado por referencias a lo cálido y lo fresco, así como a la fe en Jesús, vírgenes y santos del devocionario cristiano.

Los objetivos de este trabajo son: 1) describir las referencias al síndrome cálido-fresco, recogidas, tanto para la farmacopea vegetal, animal y mineral, como en relación a las etiologías de enfermedades-trastornos; 2) identificar los modelos etiológico-terapéuticos relacionados con el síndrome, y, por último, 3) dilucidar su articulación con otros sistemas simbólicos presentes en su medicina y con las cualidades sensibles de los remedios.

Los datos fueron obtenidos durante siete campañas realizadas entre julio de 1996 y marzo de 2000 en el oeste de la provincia de Formosa, centronorte de Argentina. Estas se desarrollaron en parajes y aldeas ubicadas hacia las márgenes del río Bermejo - al sur-, y del Bañado La Estrella -al norte-, en los departamentos Matacos y Bermejo respectivamente. Se trabajó con 83 informantes con quienes se hicieron entrevistas de tipo semiestructuradas, durante las cuales se inquirió acerca de los usos de las plantas en general, y sobre su medicina tradicional en particular. Los informantes fueron elegidos entre los miembros más ancianos de cada comunidad y sus edades oscilaron entre los 50 y los 90 años; 47 de ellos eran varones y 36, mujeres. Se efectuaron encuestas destinadas especialmente a conocer la naturaleza de las diversas enfermedades según sus creencias tradicionales. Los equivalentes científicos de las mismas son aproximados; estos fueron obtenidos en base a las descripciones que hicieran los informantes y a la bibliografía existente sobre el tema para nuestra área cultural. Las encuestas fueron registradas en cintas magnetofónicas o en cuadernos de campo.

\section{LOS "CHAQUEÑOS" DEL OESTE FORMOSEÑO}

Los criollos o "chaqueños" del oeste formoseño son los descendientes de los primeros colonos de raigambre hispano-quichua que ocuparon la región a principios del siglo $\mathrm{Xx}$, provenientes de las provincias de Santiago del Estero y de Salta principalmente. Se dedican al pastoreo extensivo de ganado vacuno y caprino sobre terrenos fiscales. La mayor parte de la

${ }^{1}$ Además de referir la identificación botánica, nombres vernáculos y parte utilizada de las plantas medicinales de los criollos, dicho trabajo enumera sus distintas formas de obtención, preparación y administración. 
población reside en el ámbito rural, con un patrón de asentamiento disperso de los puestos ganaderos. Su conformación cultural se remonta al proceso de mestizaje iniciado en el siglo xvII entre los españoles que se instalaron en las actuales provincias de Santiago del Estero, Tucumán, Salta y Jujuy, y los aborígenes por ellos sojuzgados. Como consecuencia de este proceso se conformó de manera progresiva una matriz hispano-indígena, cuyo desarrollo se llevó a cabo sin solución de continuidad durante los siglos posteriores. Practican la religión católica y son especialmente devotos de la Virgen María (en sus diversas advocaciones) y los santos, a quienes ofrecen novenas, rezos, hacen promesas y - eventualmenteprocesiones. También son afectos, aunque en menor medida, a rituales ligados a creencias del mundo andino (como la Pachamama o Madre Tierra). En general se evidencia una importante gravitación del mundo de lo sobrenatural en su forma de percibir el universo. Son comunes las referencias a potencias, espíritus o almas de los muertos, a signos del ámbito natural que evocan presagios (benéficos y malignos) y a animales míticos (madre de la hacienda), entre otros.

Desde comienzos del siglo $\mathrm{xx}$ conviven con aborígenes de las etnias wichí y toba-pilagá, con quienes mantienen relaciones signadas históricamente por un clima de tensión y recelo mutuo (Gordillo y Leguizamón 2002; Arenas 2003). Gran parte de los criollos tienen hoy un contacto fluido con el ámbito urbano, principalmente con el pueblo de Ing. G.N. Juárez, desde donde introducen nuevos elementos de la farmacopea, nomenclaturas y diagnósticos de enfermedades - principalmente a partir de su hospital-, así como toda clase de innovaciones en los más diversos aspectos de sus vidas.

Como ocurre con la mayoría de los saberes folk, sus conocimientos terapéuticos se hallan socializados en gran medida. Este corpus, conocido como "medicina casera" o autotratamiento (Menéndez 1992; Zolla et al. 1992), es compartido en forma sumamente fragmentaria por la mayoría de las familias criollas. Entre ellas, sin embargo, destacan algunas personas que saben curar determinadas enfermedades por la posesión de un "secreto". Según la frecuencia con que ejerciten estas prácticas, se les llama "curanderas" o "medio curanderas". Sin embargo, no se han registrado individuos enteramente dedicados al arte de curar, ni que hayan obtenido sus conocimientos a través de un proceso de iniciación ${ }^{2}$. Según los informantes,

\footnotetext{
${ }^{2}$ Sin embargo, seis de nuestros informantes pueden considerarse como "terapeutas tradicionales", en el sentido que le otorga la antropología mexicana: aquellas personas pertenecientes a la comunidad donde ejercen, a las que el grupo social reconoce como dotadas de conocimientos, habilidades o facultades para curar, que diagnosti-
} 
estas personas prácticamente han desaparecido del medio rural. Esto significa que la mencionada medicina casera y la cura por secreto (muchas veces sinonimizada con el nombre de curanderismo por los informantes), se hallan estrechamente vinculadas ${ }^{3}$ y ejercidas por las mismas personas.

Para trastornos menores los criollos recurren todavía a su medicina tradicional. Para ello consultan a un integrante de su familia o a una persona mayor de la comunidad, especialmente mujeres. En cualquiera de los casos se diagnostica la enfermedad y se receta un remedio. La mayoría de las formas de preparación y administración de los mismos, así como gran parte de la nomenclatura de las enfermedades, constituyen resabios de las empleadas por la medicina popular española de los siglos XVI y XVII (Di Lullo 1929, 1983; Scarpa 2000a). Para enfermedades no conocidas o, cuando el remedio casero no da resultado, recurren al hospital del pueblo más cercano o bien a personas que curen por secreto. También se dirigen a estas últimas cuando no logran sanar luego de haber estado internados en hospitales públicos.

\section{CONCEPTOS DE ENFERMEDAD Y DIAGNOSIS}

Dado que las categorías de cálido-fresco no son suficientes para explicar la totalidad de las etiologías de las enfermedades, y con el fin de situar dichas categorías en el conjunto de los modelos etiológicos presentes, es necesaria una síntesis de las representaciones de la enfermedad para los criollos.

La enfermedad y su curación, en tanto categorías culturales, se insertan siempre en el contexto de una cosmovisión determinada (Sturzenegger 1987: 2). El principio normativo o "ethos" que rige la vida de los criollos deriva de una visión del mundo acorde al dogma cristiano. Según esta fe el hombre debe vivir siguiendo el ejemplo de Jesucristo, plasmado en las sagradas escrituras, por lo cual se constituye en el arquetipo mítico de referencia, de cuyas acciones y palabras emana la noción de eficacia. Se han podido identificar en el discurso criollo las dos concepciones contrapuestas de enfermedad del ideario cristiano: la soteriológica $\multimap$ expiatoria- y la condenatoria. En cuanto a la primera, los informantes pusie-

can enfermedades conforme a una idea de causalidad que es compartida por el grupo, y cuyo sistema de creencias, conceptos y prácticas las distinguen claramente de los terapeutas de la medicina institucional" (Zolla et al. 1992: 78-79).

${ }_{3}$ Tanto es así, que ambos tipos de medicina pueden emplearse en la cura de los mismos trastornos e, inclusive, pueden aparecer superpuestas, representando cada una de ellas una de las etapas de un mismo tratamiento. 
ron énfasis en el "para qué" (o sentido último) más que en el "por qué" del origen de la enfermedad, la cual es concebida como un instrumento benéfico al homologar la curación con la "salvación espiritual"; en otras palabras, la aparición de la enfermedad brindaría la posibilidad de hacer relucir la gloria divina de Dios a través de la curación ${ }^{4}$. En la acepción condenatoria, no menos importante que la anterior, la enfermedad es explicada en términos de culpa y condena por la transgresión de la palabra de Dios y de sus normas sociales derivadas, especialmente por el incumplimiento de los mandamientos y del calendario litúrgico.

En otro plano de significaciones, la enfermedad es conceptuada, tanto de manera relacional como ontológica. Dentro del primer grupo hay que distinguir entre aquellas representaciones derivadas de una desarmonía producida en relación con la persona misma, de aquellas otras derivadas de una desarmonía con su medio social. Dentro de la primera prevalece la idea hipocrática de la enfermedad (simplificada y refigurada), manifestada por un desequilibrio producido por un exceso de lo cálido o de lo fresco, así como por "el mal estado de la sangre". Por desarmonía con su medio social se consideran aquellas enfermedades derivadas de la violación de normas sociales, entre las cuales se incluyen las que obedecen al complejo de la envidia, por concebir una criatura antes de destetar a otra, por "ojeadura" (voluntaria o involuntaria), por violación del tabú del incesto, entre otras. La idea ontológica de enfermedad, por último, fue manifestada tanto por un proceso de intrusión de un objeto externo (un mal aire, un viento, un frío, un calor, una cosa), como por un proceso de pérdida de un componente vital (pérdida del alma).

La diagnosis es efectuada comúnmente por el mismo paciente o bien por algún integrante de su familia o persona anciana de la comunidad. Al igual que lo señalado por Kuschick (1995: 69) para la medicina casera española, el diagnóstico entre los criollos se apoya en bases empíricas y se reduce a la interpretación folk de los síntomas. La sintomatología criolla se expresa principalmente a través de la topografía del dolor o de la aparición de alteraciones en la superficie de la piel; éstas últimas interpretadas como provenientes del mal estado de la sangre. Merecen especial referencia los síntomas folks interpretados como "frialdad", "chujcho", "ardor", "quemazón" y "fiebre". Otros síntomas consignados con menor

\footnotetext{
${ }^{4}$ Sendrail (1983) y Laplantine (1999) también señalan esta concepción para pueblos campesinos europeos.

5 La descripción de este trastorno se realiza en el punto V.

${ }^{6}$ Aunque la fiebre es tratada especialmente como una enfermedad, también se la menciona frecuentemente como síntoma de heridas, insolación, dolor de cabeza y otros trastornos folks.
} 
frecuencia son el color de la orina y de la materia fecal, vómitos, sudoración profusa, pérdida del apetito, signos de debilidad, etc.

Entre los nombres y diagnósticos de enfermedades que los criollos incorporan de la consulta clínica en hospitales $-\mathrm{y}$ de otras personas relacionadas con los ámbitos citadinos-, figuran el "cáncer"; los "cálculos a la vesícula", el "dolor al hallacuchillo" (páncreas); bronquitis y gripe.

\section{El SÍNDROME CÁLIDO-FRESCO}

La caracterización fresco-cálida de enfermedades, remedios, alimentos, ambientes y acciones alude, tanto a una naturaleza térmica como metafórica. Es decir, refiere, tanto una sensación que provoque frío o calor en el cuerpo humano - por ejemplo alimentos grasos, fiebres, ardores, efectos refrescantes, sudoríficos, vientos, aires, trabajo duro-, como también una "virtud" o naturaleza intrínseca de la enfermedad, alimento, remedio o ambiente, no relacionada con una caracterización de índole térmico. Tanto Sturzenegger $(1985,1999)$ como Foster $(1953,1994)$, Queiroz (1984) e Idoyaga Molina (2000) establecen la misma caracterización de los componentes del síndrome para sociedades campesinas latinoamericanas. A continuación se describe la caracterización de la farmacopea y los alimentos según el síndrome, realizada por los informantes.

\section{IV.1. La farmacopea y el sindrome}

La principal práctica terapéutica entre los criollos consiste en la administración de remedios de su farmacopea. Sin embargo, se debe destacar que poseen otras técnicas curativas (religiosas especialmente) que no incluyen estos tipos de elementos, tales como la "cura de palabra" o a través del "secreto", la cura "por el rastro" y a través de ritos de carácter purificatorio. Las relaciones entre estas otras formas de curación y el síndrome aquí tratado se discuten en el punto VIII.

Buena parte de su farmacopea fue caracterizada según el síndrome. Dentro de ella, las plantas constituyen el remedio por excelencia de los criollos; sus técnicas de preparación y administración son muy variadas (Scarpa 2004), aunque la principal consiste en preparar una decocción que se administra por vía oral. Resultó existir un gran consenso acerca de las cualidades cálido-frescas de 66 especies o partes vegetales; 23 de las cuales son cálidas y 43 frescas. Entre las primeras, a modo de ejemplo, refirieron el "guayacán" (Caesalpinia paraguariensis); el "cabrayuyo" (Solanum argentinum); el "palo santo" (Bulnesia sarmientoi) y la "ruda" (Ruta 
chalepensis). Entre las plantas "frescas" figuran el "cepacaballo" (Xantbium spinosum), el "malvisco" (Sphaeralcea bonariensis); la "vila-vila" (Solanum sisymbriifolium) y la "tramontana" (Funastrum gracile). Entre estas últimas, seis fueron categorizadas como "muy frescas" en solo seis referencias. En solo cuatro casos no hubo consenso acerca de la categorización respectiva. Se pudo comprobar además, que en la mayoría de los casos, las plantas cálidas se toman "por té" y las frescas "por agua" no se cumple este patrón son analizados en el ítem VI.3.

A diferencia de los remedios vegetales, el uso de la farmacopea animal y mineral es menos frecuente y mayoritariamente se administra de forma externa. Sólo 26 de estos elementos fueron caracterizados según el síndrome. Como elementos cálidos se refirieron con alto grado de consenso el estiércol de vaca, de vizcacha (Lagostomus maximus) y de burro, las mieles, grasas de cabra, de vaca, carpincho (Hydrochoeris bydrochoeris), comadreja (Didelphis azarae), gallina, iguana (Tupinambis sp.), león (Puma concolor), oso hormiguero (Myrmecophaga tridactyla), quirquincho (Chaetophractus villosus), suri (Rhea americana), tigre (Panthera onca), zorro (Pseudalopex gymnocercus) y zorrino (Conepatus suffocans); la hiel vacuna, la yema de los huevos; la leche de burra, de cabra y de yegua. Entre los elementos frescos se mencionó la piel y la grasa de los sapos, la clara de los huevos, el suero de la leche vacuna y el "unto de chancho" ${ }^{8}$. Por otra parte, entre los productos minerales frescos encontramos principalmente el agua fría, la sal, el bicarbonato de sodio, el alumbre, el jabón blanco y el vinagre. Entre los cálidos los informantes refirieron el azúcar, el azufre, el gas-oil y el queroseno. Finalmente, dos fármacos manufacturados fueron también categorizados como frescos: el "mentisan" 9 y la aspirina.

\section{IV.2. Los alimentos y el sindrome}

La caracterización de los alimentos según el síndrome se realiza frecuentemente con fines preventivos y, en menor medida, cuando se pres-

\footnotetext{
${ }^{7}$ Tomar un remedio vegetal por agua significa ingerir una decocción preparada con abundante cantidad de agua (medio litro, un litro o más), a temperatura ambiente y en diferentes tomas a lo largo del día, es decir "como se toma el aguan. Tomar un remedio "por té" significa beber la decocción lo más caliente posible en pequeñas cantidades (una taza o menos) y sólamente una vez al día - frecuentemente en ayunas.

${ }^{8}$ Grasa del cerdo de consistencia correosa.

9 Ungüento con fuerte olor a menta que se comercializa en los mercados como producto manufacturado de origen boliviano.
} 
cribe su ingesta con fines terapéuticos. Los alimentos muy ricos en calorías o picantes y ciertas bebidas estimulantes fueron catalogados como cálidos; éstos son el asado (carne vacuna), la carne asada de cabra y de la mayoría de los animales del monte, los guisos, las sopas, el "frangollo", el "locrillo", el "picante", "anchi"; "anchapi", "mazamorra", el "trigo en sopa", el "bolanchao" ${ }^{10}$, el maíz tostado con azúcar, todos los tipos de miel, la grasa asada, los frutos del "algarrobo blanco", "chañar", "mistol" y del "aji del monte" ${ }^{11}$, la leche vacuna, el aceite comestible, el azúcar, el café, el mate y las bebidas alcohólicas (estos tipos de alimentos predominan en la dieta criolla). Los alimentos no tan cálidos - ninguno sería totalmente fresco-, se consideran menos nutritivos que los cálidos y de fácil digestión; tales son las verduras, la milanesa, el "salpicado" ${ }^{12}$; la carne de gallina, de pollo, de "carpincho", el almidón de mandioca y el del "malvisco" - extraído de sus raíces-, la maizena, el vinagre, los frutos del "cardón" y los de la "sacha sándia" ${ }^{13}$.

Por último, el excesivo calor ambiental, una prolongada exposición al sol, el viento norte, el trabajo duro y las maderas ásperas al tacto —cuando son usadas para confeccionar mangos-, recibieron la caracterización de cálidas. El viento sur, una prolongada exposición "al sereno" (rocío), el reposo y las maderas suaves al tacto fueron caracterizadas como frescas.

\section{TRASTORNOS CÁLIDOS Y FRESCOS}

Lo cálido y lo fresco participan, tanto en concepciones ontológicas como relacionales de la enfermedad. En el primer caso, los criollos refirieron como causas de sus enfermedades y como características de diversos síntomas a "un calor" o "una frialdad" ubicada en un locus determinado. Así, diagnósticos tales como "frío al estómago", "calor a los intestinos"

\footnotetext{
${ }^{10}$ Frangollo: Especie de polenta preparada con maíz molido grueso. Locrillo: Potaje a base de harina de trigo, porotos, papa, zapallo y trozos de cerdo. Picante: Adobo preparado con aceite, vinagre, ajo, ají del monte y sal, empleado para sazonar carnes asadas. Anchi: Postre que resulta de la cocción de sémola de maíz y azúcar, aromatizado con vainilla o clavo de olor. Anchapi: Sopa de harina de maíz tostado. Trigo en sopa: Sopa de harina de trigo. Bolanchao: Bolillos hechos con frutos molidos de "mistol" (Zizyphus mistol), impregnados por una capa delgada de harina de algarroba o, menos frecuentemente, de maíz tostado.

${ }^{11}$ Respectivamente: Prosopis alba; Geoffroea decorticans; Z. mistol y Capsicum chacoense.

${ }^{12}$ Especie de ensalada a base de pollo, papas y/o zanahoria hervida y mayonesa.

${ }^{13}$ Respectivamente: Stetsonia coryne y Capparis salicifolia.
} 
o "frío en los huesos" —entre otros-, revelan la presencia de "una cosa" en "algún lugar". En menor medida, los componentes del síndrome - como agentes etiológicos- se piensan en términos de graduaciones en la forma de un "exceso" de alguno de ellos. Así, el "desarreglo de vientre" sobreviene cuando "tiene muchas calorías en los intestinos"; las "quemazones al orinar" cuando "tiene muchas calorías en la vejiga", el "frío a los huesos" cuando tienen "muchas helazones", y trastornos digestivos "cuando comen muchas cosas cálidas, muy pesao". Este desequilibrio, puesto de manifiesto principalmente en la noción de "desarreglo", obedecería a un modelo etiológico de carácter funcional o relacional.

Un total de 29 tipos de trastornos fueron caracterizados como "cálidos" en 97 referencias totales. La casi totalidad de los trastornos digestivos son de etiología cálida; mucho de ellos —como el "empacho" ${ }^{14}$ y otras indigestiones- originados por comer demasiados alimentos de ese signo. Toda alteración que aparece en la piel es considerada como efecto de "un calor que sale de adentro", "un ardor", debido a "sangre enalterada" o "mala sangre". Toda inflamación ya sea originada por paperas, golpes, diviesos ("chupos" y "granos"), heridas o quemaduras, así como todo eczema o sarpullido son caracterizados como un calor o una fiebre. La insolación, el dolor de cabeza, la fiebre, la "fiebre interior" ${ }^{15}$, la "mala sangre", los resfríos y la tos del verano son trastornos cálidos.

Un total de 14 tipos de males fueron caracterizados como "una frialdad" o "un frío" en 38 referencias totales. Poseen esta etiología todos los trastornos del aparato respiratorio y del sistema ósteo-muscular. Según los informantes el frío es responsable de la interrupción o "corte" de la menstruación; de la imposibilidad de parir - la temperatura se toma en la mollera- y del "sobreparto" ${ }^{16}$. Con el nombre de "chujcho" los informantes hicieron referencia a una enfermedad -el paludismo- y a uno de los síntomas originados por picaduras de arañas y de víboras ${ }^{17}$. El dolor de

\footnotetext{
${ }^{14}$ Indigestión aguda ocasionada por una "detención" de los alimentos en el tracto digestivo. Sus síntomas son mareos y diarrea profusa de materia fecal marrón-amarillenta.

${ }^{15}$ Fiebre y "fiebre interior" son enfermedades folks, descritas como un calor $\mathrm{o}$ inflamación interna respectivamente, sin localización expresa.

${ }^{16}$ A este respecto, García y Jiménez (1986: 139) para el litoral argentino y Cosminsky (1992) para la medicina popular mexicana, señalan que en el momento del parto el niño se lleva consigo todo el calor de la madre, por lo cual esta queda en un estado de extrema frialdad y, por ende, muy sensible al frío. Remedios calientes y dieta con alimentos cálidos reestablecen el equilibrio perdido.

17 Se trata de un intenso frío sentido en todo el cuerpo que alterna con síntomas febriles. Cuando esto último sucede se dice que "prende el chujcho".
} 
oídos y el "frío al estómago" ${ }^{18}$ también fueron referidos como trastornos frescos.

Por último, los informantes coinciden en que el reuma y el dolor de muelas pueden originarse tanto por un "calor" como por un frío. Los síntomas que producen las picaduras de viboras fueron caracterizados como calores (en cuanto a la inflamación que provocan) y escalofríos o "chujcho", percibidos alternadamente.

En resumen, las etiologías de 46 tipos de trastornos fueron caracterizadas según el síndrome en 142 referencias totales con un nivel de consenso mayor del $95 \%$.

\section{ANÁLISIS RELACIONAL DE REMEDIOS Y ETIOLOGÍAS. MODELOS IDENTIFICADOS}

Con el fin de dilucidar los modelos etiológico-terapéuticos asociados al síndrome, se analizan las relaciones que los informantes establecieron entre las distintas categorías de remedios y etiologías. En el cuadro 1 se contabiliza el número de trastornos cálidos y frescos que se tratan con remedios caracterizados de esta misma manera.

\section{CUADRO 1}

NÚMERO DE REMEDIOS SEGÚN LA ETIOLOGÍA DEL TRASTORNO

\begin{tabular}{|c|c|c|c|c|}
\hline \multirow{3}{*}{$\begin{array}{c}\text { TIPOS } \\
D E \\
\text { REMEDIOS }\end{array}$} & \multicolumn{4}{|c|}{ ETIOLOGIA DE LOS TRASTORNOS } \\
\hline & \multicolumn{2}{|c|}{ Cálidos } & \multicolumn{2}{|c|}{ Frescos } \\
\hline & Trastornos & $\%$ total & Trastornos & $\%$ total \\
\hline Cálidos & 12 & 40 & 14 & 100 \\
\hline Frescos & 28 & 90 & 1 & 6 \\
\hline
\end{tabular}

Sobre un total de 29 trastornos cálidos y 14 frescos.

De acuerdo a estos resultados se pudieron distinguir dos grupos de relaciones entre remedios y etiologías: de oposición y de homologación.

${ }^{18}$ Como el empacho, también fue caracterizado como indigestión aguda, seguida de diarrea profusa, pero a diferencia de este, es producido por un frío, y el color de la materia fecal es verdoso. 


\section{VI.1. Relaciones de oposición. Modelo alopático}

Los informantes hicieron explícita referencia en su discurso a la relación por la cual trastornos de etiología cálida se curan con remedios frescos y viceversa, tanto en términos generales como para casos específicos. Como ejemplo de esto último podemos referir:

Mi padre decía este yuyito es fresco, este es cálido, nos hacían baños cuando había frialdad... hacían baños con yuyos cálidos... y cuando había así calenturas... vamo'a decir ya le daban los yuyitos frescos.

En cuanto a la alimentación los informantes más ancianos coincidieron en señalar que en el pasado se respetaba el criterio de ingerir en forma equilibrada alimentos frescos y cálidos con fines preventivos. La excesiva participación de alimentos cálidos en su dieta, debía ser compensada con hierbas o alimentos de naturaleza fresca para evitar indigestiones. En el mismo orden de cosas, también se prescriben dietas especiales con fines preventivos, como por ejemplo, para evitar el "sobreparto" (de etiología fresca) es beneficioso para las mujeres comer cosas cálidas y evitar el consumo de alimentos muy frescos durante el período del puerperio. Cuando amamantan, en cambio, deben evitar alimentos cálidos para no "pasarle" el empacho a los lactantes.

En efecto, los resultados del cuadro 1 muestran que el criterio de los contrarios se cumple para el $90 \%$ de los trastornos cálidos y para el $100 \%$ de los trastornos frescos. Según los informantes, dicho criterio persigue la reabsorción de un exceso por su opuesto; así lo fresco "chupa", "saca", "absorbe" o "amortigua" los calores y viceversa. Estos tipos de aplicaciones sugieren la presencia del principio de oposición o doctrina de los opuestos de la antigua medicina hipocrático-galénica. Este criterio terapéutico es el predominante en la mayoría de las sociedades folk de Hispanoamérica según Foster (1979).

Sin embargo, al preguntar acerca de si cualquier planta fresca podría emplearse contra cualquier trastorno de etiología cálida y viceversa, los informantes se mostraron confundidos, hicieron un largo silencio significativo o bien lo negaron de plano. La explicación última dada coincidió en que lo que opera es la "virtud" o el "poder" del remedio, y que "ellos aprendieron así", que "es lo que se acostumbra"; esto es, una noción que alude a una particular especificidad del remedio (ver Discusión). Similares datos ha obtenido Sturzenegger (1999) entre los criollos de Las Lomitas. 


\section{VI.2. Relaciones de bomologación. Modelo bomeoterápico}

Para el $40 \%$ de los trastornos de etiología cálida (12), sin embargo, los criollos administran remedios del mismo signo. Al inquirir sobre el fin perseguido en estas prácticas, que no cumplen el modelo de los contrarios, las referencias de los informantes fueron del tipo "así es la costumbre", "así aprendimos". Sin embargo, en su discurso sobre las curaciones específicas de este tipo, como en el caso del sarampión, refirieron que los remedios cálidos se aplican con el fin de "hacerlo brotar", para "que no se vaya p'adentro", o para que la enfermedad "prenda o apure" o que "tiene que madurar la enfermedad", al referirse al sarampión y a la fiebre en la enfermedad del "chujcho"; a la necesidad de "madurar" los forúnculos; de "asentar la comida" (que "baje" como es natural) para casos de indigestión; o "para que transpire" en casos de insolación y fiebres y así "salga el calor pa' fuera”. Nos encontramos aquí con una estrategia terapéutica de índole resolutiva, tendente a provocar la excitación de funciones orgánicas normales del cuerpo con el fin de favorecer el rápido desarrollo del trastorno. Entre estas estrategias, una de las más empleadas por los criollos, es la de favorecer los mecanismos de evacuación naturales del organismo, a través de la administración de purgantes ${ }^{19}$ y sudoríficos principalmente. De esta manera, los remedios cálidos se emplearían con el fin de excitar la función intestinal en el tratamiento del empacho y otras indigestiones; la función estomacal (en el caso de los digestivos o "asentativos"), la función hepática ("mal al hígado"). El uso de condimentos pungentes (cálidos) como aderezo de las carnes con el fin de favorecer su digestión, se inscribe dentro de esta estrategia terapéutica ${ }^{20}$. El mismo principio regiría la aplicación de remedios cálidos como madurativos de abscesos. Igualmente en el tratamiento contra las quemaduras, el "aire" ${ }^{21}$, la fiebre, la "fiebre interior" y la insolación, los remedios cálidos administrados tienen el objeto de "hacer salir el calor" o "chupar la fiebre". El empleo de sudoríficos en los últimos tres casos, tendría como finalidad promover la evacuación de dicho calor a través de la transpiración.

\footnotetext{
19 La famosa tríada de la purga, el enema y la sangría ha quedado reducida a la primera técnica, como modelo terapéutico netamente extractivo de los "malos humores" corporales. La enema y la sangría persisten de manera relictual en la veterinaria tradicional de estos criollos.

${ }^{20}$ Tal tratamiento buscaría promover la digestión a través de la irritación de las vellosidades intestinales.

21 Distinguimos en este trabajo, al igual que Palma (1978), dos tipos de "aire": El "mal aire" de características mortales y de terapéutica exclusivamente ritual, y el "aire" a secas, que en nuestra zona fue referida para eczemas y dolor de oídos principalmente.
} 
Acorde al mismo criterio, en ciertos casos se recomienda sencillamente aguardar a que el trastorno se desarrolle normalmente con el tiempo ${ }^{22}$. Esta última modalidad constituye una variación de las anteriores, aunque de tipo no intervencionista.

Todas estas técnicas terapéuticas responden al modelo conocido como "homeoterápico" u "homeopático", el cual es citado en la medicina popular del Noroeste argentino sólo para el sarampión por Idoyaga Molina (2001: 25), en la medicina popular mexicana por Zolla et al. (1992), y en la francesa por Laplantine (1999: 194). Según este último, para las inflamaciones se recetan remedios cálidos, para las quemaduras se actúa aplicando "fuego contra fuego" mediante compresas de vinagre o alcohol, o incluso calentando la parte quemada. Contra las fiebres se recetan infusiones calientes, potajes, tisanas, incluso inhalaciones hirvientes, con el fin de hacer enrojecer y transpirar, de ayudar a la expulsión del calor extrayéndolo mediante cataplasmas y caldos. En lugar de ser un síntoma a anular, la evacuación (bajo la forma de heces o sudor), es un proceso que conviene facilitar e incluso provocar, pues haciendo salir del cuerpo los "humores malignos" se conduciría al enfermo a su "curación" (Laplantine 1999: 191-194).

\section{VI.3. Modelos terapéuticos mixtos}

Para cierto grupo de trastornos los modelos antes identificados se aplican, tanto en forma alternativa como complementaria. El primer caso corresponde al tratamiento de diviesos (granos y forúnculos), fiebres, heridas, quemaduras y de los trastornos hepáticos, todos de etiología cálida. Aunque su tratamiento responde mayoritariamente al modelo alopático, alternativamente se sigue el modelo homeoterápico administrando remedios cálidos. En ocasiones algunos de estos remedios son aplicados a la usanza de los frescos, es decir, "por agua", en forma de baños fríos y de "agua enserenada" (fría). Estas combinaciones responderían al hecho de atenuar las propiedades cálidas de los remedios, con el fin de no agravar en demasía el trastorno a curar. Este tipo de atenuación de las propiedades cálido-fresca de los remedios es citado frecuentemente para otras medicinas folks (Sturzenegger 1999; Palma 1978, Queiroz 1984).

En el tratamiento de la insolación y del "chujcho", los modelos alopático y homeopáticos operan de manera complementaria, representando dos fases

\footnotetext{
${ }^{22}$ En tal sentido los informantes refirieron expresiones de este tipo: "...hay que esperar... despacito sale esa maldad"; "dejar que prenda" el chujcho, "que brote" el sarampión.
} 
de la misma curación. La insolación se trata principalmente con remedios frescos aunque, en ocasiones, se administran conjuntamente remedios cálidos con el fin de "extraer" ese calor y así evitar el perjuicio del "pasmo" 23 . Para el "chujcho" los criollos esperan a que "prenda" la enfermedad - actitud expectante típicamente homeopática-, para luego, con la aparición del síntoma febril, tratarlo con remedios frescos según el modelo alopático.

El tipo y número de aplicaciones medicinales registradas en relación a los modelos operantes según el síndrome, concuerdan con el análisis cualitativo antes realizado. En el cuadro 2 se ordenan los resultados cuantitativos totales para cada uno de los modelos.

\section{CUADRO 2}

APLICACIONES MEDICINALES Y REFERENCIAS TOTALES REGISTRADAS PARA CADA UNO DE LOS MODELOS IDENTIFICADOS

\begin{tabular}{|c|c|c|c|c|}
\hline \multirow{3}{*}{$\begin{array}{c}\text { MODELO } \\
\text { ETIOLÓGICO-TERAPÉUTICO }\end{array}$} & \multicolumn{4}{|c|}{ TIPOS DE REMEDIOS } \\
\hline & \multicolumn{2}{|c|}{ Frescos } & \multicolumn{2}{|c|}{ Cálidos } \\
\hline & Aplicaciones & Referencias & Aplicaciones & Referencias \\
\hline Alopático & & & & \\
\hline Etiologías cálidas & 106 & 378 & 16 & 22 \\
\hline Etiologías frescas & 10 & 13 & 103 & 247 \\
\hline Homeopático* & 6 & 8 & 27 & 91 \\
\hline Mixto* & 72 & 252 & 30 & 58 \\
\hline Total analizado & 194 & 651 & 176 & 418 \\
\hline
\end{tabular}

* Evidenciado solo para etiologías cálidas.

Es interesante señalar que de los 370 remedios analizados, el 78\% (291) se aplican siguiendo el modelo alopático (incluyendo los 72 correspondientes al modelo mixto) para el tratamiento de 38 tipos de trastornos, mientras que sólo el 15\% (57) de los remedios se aplican según el modelo homeoterápico para 11 afecciones.

${ }^{23}$ Trastorno cuyo síntoma característico es la sudoración profusa, producida a la menor sensación de calor. Esto sucede cuando el cuerpo queda excesivamente cálido como producto de no haber extraído el calor de la insolación, el cual "queda adentro". 


\section{ETIOLOGÍAS Y REMEDIOS NO CARACTERIZADOS SEGÚN EL SÍNDROME}

Los modelos como construcciones teóricas en etnociencia tienen por objeto establecer hipótesis en torno a los patrones que rigen determinadas prácticas, especialmente, como apunta Laplantine (1999: 40), poner en evidencia lo que ellas no dicen. Un importante número de trastornos y remedios no fue caracterizado ni como cálido ni como fresco ${ }^{24}$. Sin embargo, para 11 de dichos trastornos los informantes administran remedios referidos expresamente como cálidos y/o frescos, mientras que 45 remedios no categorizados son aplicados para trastornos caracterizados según el síndrome. En virtud de los modelos etiológico-terapéuticos identificados, analizaremos el grado de articulación de estos tipos de relaciones entre trastornos y remedios.

\section{VII.1. Etiologias no referidas}

Un total de 90 aplicaciones medicinales cálidas y frescas de la farmacopea son destinadas a trastornos no caracterizados según el síndrome. Para cada uno de ellos, sin embargo, los informantes coincidieron en el $90 \%$ de los casos, con el tipo de terapia cálido-fresca administrada.

Para los "cálculos a la vesícula" se refirieron únicamente remedios frescos, lo cual se articula coherentemente con el modelo alopático antes señalado, ya que la casi totalidad de las etiologías del sistema digestivo obedece a un exceso de lo cálido. La aplicación de remedios cálidos como vermífugos tendría la intención de excitar la función intestinal a fin de evacuarlos; mientras que los empleados "pa'l constipao" (estreñimiento) operarían como purgantes, por lo que la terapéutica se ajusta al modelo homeoterápico sustractivo. Como oxitócicos y abortivos se emplean remedios cálidos; su acción perseguiría los mismos fines que los utilizados como emenagogos y para favorecer el parto, es decir, producir una evacuación desde el útero. En los cuatro casos coinciden el signo del remedio administrado e inclusive los mismos remedios; estas terapéuticas responden al modelo alopático. A la misma lógica responde el uso de remedios frescos como antiemenagogos ya que, como vimos, el frío ambiental es responsable de la suspensión de la menstruación.

${ }^{24}$ Trastornos y aplicaciones medicinales de este tipo fueron: los antivenéreos, galactogogos, "dolor de costado" (pleuresía), dolor menstrual, "cancha" (micosis), cicatrizantes, "Susto", la "aicadura", las "tejtes" (verrugas), "culebrilla" (herpes zoster), los antiabortivos, "cáncer" y mal de ojo u "ojeadura", entre otros. 
La aplicación de remedios cálidos contra la "sarnilla" — descrita como un eczema extendido-, seguiría el modelo terapéutico homeopático; la finalidad última sería la de extraer el calor como en el caso del sarpullido extendido, producido por el sarampión. El tratamiento del dolor de garganta con remedios cálidos es del todo acorde con la etiología predominante de los trastornos del sistema respiratorio: el frío; opera el modelo alopático. Los informantes señalaron que el calor ambiental sofocante "enaltera" la sangre, la hace "gorda" y baja la presión. Por lo cual, es totalmente lógico desde su perspectiva la administración de remedios frescos como hipertensores. Por último, se aconseja como preventivo "curar el agua" de bebida añadiéndole partes vegetales referidas como cálidas - especialmente duramen de palo santo-, así como calentar el agua destinada para baños con plantas cálidas. En ambos casos, procurarían prevenirse de los efectos frescos dañinos, referidos para el "agua cruda" (sin "calentar").

\section{VII.2. Remedios vegetales no caracterizados según el sindrome}

Un total de 45 plantas medicinales no categorizadas según el síndrome pero administradas contra trastornos cálidos o frescos, poseen al menos 2 usos medicinales cada una e involucran un total de 133 aplicaciones. Al contabilizar el número de recetas en las que dichos remedios se administran para trastornos de terapia cálida y fresca (independientemente de su etiología específica), se puso de manifiesto que el $76 \%$ de ellos se comportan claramente como remedios cálidos o frescos en el $72 \%$ de las aplicaciones. En efecto, 13 de ellos actúan claramente como remedios frescos en un total de 34 aplicaciones medicinales y 21 como cálidos en 61 aplicaciones. Los restantes remedios vegetales (11), o bien no actúan según el síndrome, o lo hacen según el modelo alopático-homeopático (trastornos no considerados), o bien no contamos con el suficiente número de datos como para esclarecer su comportamiento.

\section{ARTICULACIÓN DE LO CÁlIDO-FRESCO CON OTROS SISTEMAS SIMBÓlICOS}

A pesar de que Di Lullo (1929) y Palma (1978) citan para el Noroeste de Argentina referencias al síndrome en oraciones y plegarias utilizadas para curar "por secreto" (el credo como cálido y el padre nuestro como fresco), y aunque se indagó específicamente sobre este tema, no se ha evidenciado correspondencia alguna con lo cálido y lo fresco entre los criollos. 
En el sahumado de casas y corrales, y en las libaciones con ocasión de fechas de alta significación en la vida espiritual del criollo como el 1. de agosto, el Viernes Santo y el día de San Juan, intervienen siempre elementos caracterizados como cálidos. Los informantes señalaron que todo el mes de agosto es malo, y que el día primero, especialmente, la madre tierra "lo viene a llevar a uno", o bien que la tierra "lo agarra". Como prevención los criollos deben "quitar el mal aire" de las casas que en esos días provoca enfermedades y hasta la muerte, mediante sahúmos con palo santo, yerba, queroseno, ruda, azufre, etc. ${ }^{25}$ También se toma una bebida alcohólica, preferentemente mezclada con ruda. En Viernes Santo y en el día de San Juan también se sahuma y se suele beber vino caliente. Lo cálido en estos ritos de carácter purificador - incluido el hecho de comer abundante-, estaría asociado a la necesidad de protegerse de una presencia negativa caracterizada por provocar la muerte, provenir de la tierra y ocurrir durante el mes de agosto. Todas estas características relacionan esta faceta maléfica de la "Madre Tierra" con lo frío, por lo cual dicho rito respondería a un modelo alopático ritual. La asociación de los "aires" con lo frío fue registrada entre los criollos (en el aire del sobreparto y en la otitis), así como en comunidades mestizas mexicanas (Álvarez Heydenreich 1992). El empleo de elementos cálidos durante estos ritos también fue señalado por Idoyaga Molina (2001) para el Noroeste argentino.

Por otra parte, el modelo alopático de reabsorción por los opuestos se complementa frecuentemente con mecanismos de adjunción de potencia como parte del mismo tratamiento. Ejemplo de ello es la cura del sobreparto - trastorno de etiología fresca-, en la cual, además de recetar una decocción de un remedio cálido, una curandera completa la curación a través del "secreto". Esta modalidad terapéutica incluye el pronunciamiento de fórmulas secretas, que pueden incluir invocaciones a ciertos Santos del devocionario criollo. Asimismo, tanto en la forma de preparación como administración de los remedios que responden al síndrome, se verifica la presencia sistemática del número 3,5 o 9 , tanto en la cantidad de tipos de remedios utilizados, partes empleadas y también en las dosis administradas. Como es sabido, corresponden a números potentes de la cultura cristiana. Asimismo, la "fe en Nuestro Señor" fue referida como indispensable para la efectividad de cualquier remedio entre los criollos, incluidos los que obedecen a los modelos mencionados.

${ }^{25}$ A pesar que en el mundo andino también se realizan estas prácticas con fines preventivos, éstas se diferencian con las del Chaco por estar acompañadas de ceremonias propiciatorias destinadas a promover la fertilidad de los campos y la fecundidad de los ganados en medio de un clima festivo (Mariscotti de Görlitz 1978; Torres 1982). 
En todos los casos, estos ritos, actitudes y elementos simbólicos operan reforzando o potenciando la efectividad del remedio. Tal como señala Idoyaga Molina (2000: 270), muchos de los criterios de la teoría humoral fueron refigurados al divulgarse en los medios mestizos latinoamericanos, y el par de opuestos sobreviviente se habría articulado con otros sistemas simbólicos que incorporan nociones mítico-religiosas y la manipulación de lo sagrado para explicar la enfermedad y la práctica terapéutica.

\section{ARTICULACIÓN DE LO CÁLIDO-FRESCO CON CUALIDADES SENSIBLES}

¿Según qué criterios una planta es considerada cálida o fresca? ¿Existe alguna relación entre esta clasificación y su morfología, hábitat, sabor, aroma u órgano empleado? Como vimos, la cualidad cálido-fresca de los remedios se define por oposición a la etiología del trastorno contra el cual produce una sensación de eficacia. Así, si un remedio vegetal es eficaz para los trastornos hepáticos entonces dicho remedio es fresco, y si es bueno para el "chujcho", es cálido. En el mismo sentido, Currier (1966: 251) señala que la clasificación de alimentos y hierbas medicinales según el síndrome frío-cálido es independiente de cualquier característica observable en forma directa, tales como forma, color, textura y temperatura física, y es descrita sólo por los efectos que tiene sobre el cuerpo humano.

Sin embargo, una serie de observaciones contradicen lo anterior. En el $72 \%$ de las 82 indicaciones medicinales donde participan las raíces, se prescriben para enfermedades de terapia típicamente frescas; de hecho se señaló que "por estar debajo de la tierra, las raíces eran frescas". Aunque para las flores el número de indicaciones fue escaso (17), se halló que en el $70 \%$ de las mismas eran prescritas como un remedio cálido según el modelo alopático. Asimismo, varias veces se informó que todas las plantas acuáticas (flotantes y sumergidas) "tienen que ser frescas". En el mismo sentido, el sabor amargo de ciertos remedios se asocia a su condición de cálido, como en el caso de la albura de quebracho blanco (Aspidosperma quebracho-blanco), del guayacán, la yerba y la coca (Erytbroxylon coca). Aromas intensos y sabores fuertes, pungentes, se asocian también con remedios cálidos, como en los casos de la ruda, ajo, tabaco, "salvia de Castilla" (Lippia alba), "ajenco", "ají del monte", eucalipto, perejil, laurel, raíz de "sacha café" (Senna occidentalis), azufre quemado, alcohol, café y grasas de animales silvestres. Similar observación es realizada por Idoyaga Molina (1999a: 14). Por último, aquellas partes vegetales especialmente referidas como duraderas, resistentes y fuertes fueron caracterizadas como cálidas; como por ejemplo, el duramen de "palo 
santo", de "quebracho colorado" (Schinopsis lorentzii), raíz de "quiebra'arao" (Heimia salicifolia), de "sacha café", etc. A la inversa, las hierbas con hojas gráciles y tiernas o de tallos carnosos, fueron catalogadas como frescas. Tales son los casos del "palán" (Nicotiana glauca), "chamico" (Datura ferox), ricino (Ricinus communis), "paletaria" (Parietaria debilis), "atacos" (Amaranthus spp.), entre otros.

En suma, en muchos casos - aunque no en todos- los criterios seguidos en la categorización de la farmacopea según el síndrome se ligan a cualidades sensibles, ya sea de los propios remedios, como de la sensación de efectividad contra clases de dolencias previamente clasificadas. Como sostiene Lévi-Strauss (1994: 34), aunque no haya conexión necesaria entre las cualidades sensibles y las propiedades, existe por lo menos una relación de hecho en gran número de casos, y la generalización de esta relación, aunque no esté fundada en la razón, puede ser durante largo tiempo una operación fructífera, tanto en la teoría como en la práctica.

\section{DISCUSIÓN Y CONCLUSIONES}

Según Erwin Ackerknecht "la medicina popular contiene elementos primitivos, pero en la misma medida o quizás más posee elementos degenerados de medicina científica, de medicina oficial. Me atrevería a afirmar que la medicina popular actual posee alrededor de un $10 \%$ de medicina primitiva y un $90 \%$ de galenismo, por decirlo toscamente" (Walser y Koelbing 1971: 10). Esto es también coherente con lo señalado por Laplantine (1999) en cuanto a que buena parte de la medicina "popular" no es ni más ni menos que la medicina oficial y "docta" de siglos precedentes ${ }^{26}$. Aunque tales afirmaciones obviamente variarán según el grado de aislamiento, dinámica y tipo de sociedad nacional con la que esté en contacto la sociedad folk considerada, las semejanzas con nuestros resultados son evidentes. Tal como apunta Kuschick (1995), la medicina popular ha estado siempre en contacto permanente con las prácticas médicas de la "Gran Tradición", absorbiendo con el tiempo creencias y prácticas que reflejan esa situación de contacto.

Gran parte de las etiologías y de las terapias referidas directa e indirectamente de acuerdo al síndrome en este trabajo, coincidieron con lo registrado para la medicina popular de otros campesinos hispanoamericanos (Mantegazza 1949; Bianchetti 1989; Katz 1997; Idoyaga Molina 2000;

${ }^{26}$ De hecho, nuestra medicina científica, hasta mediados del siglo XIX, prácticamente no administraba otro medio terapéutico que no fuese la intervención sustractiva basada en la famosa trilogía: enema, purgante y sangría (Laplantine 1999: 205). 
Queiroz 1984; Currier 1966; Cadogan 1957; Palma 1978). Esto coincide con las afirmaciones de Foster (1979) con respecto a la gran homogeneidad de este síndrome para toda esta región.

Nuestros resultados mostraron tres diferencias importantes con respecto al trabajo de Sturzenegger (1999) - mencionado en la introducción-. En primer lugar, como la mayor parte de los autores describen para otras regiones de América Latina, las nociones de cálido-fresco enunciadas por los criollos del oeste de Formosa aparecen caracterizando etiologías, remedios y alimentos en términos de oposición binaria y no de un continuum de gamas de intensidades como es referido por la citada autora. En efecto, de las 65 especies vegetales sólo seis fueron caracterizadas como "muy frescas" en seis referencias totales. Otra de las diferencias, y además uno de los aspectos más significativos de estos resultados, es la identificación del criterio homeoterápico. De hecho, gran parte de la bibliografía consultada sobre el síndrome en Latinoamérica menciona como único modelo patogénico-terapéutico relacionado con lo cálido-fresco al principio de oposición. Sin embargo, Queiroz (1984: 54) a pesar de explicar la lógica de las prácticas terapéuticas en base a dicho principio, destaca que sus informantes Caiçaras alegan que "muchas enfermedades necesitan completar enteramente su ciclo de desarrollo, y que el tratamiento debe ayudar al desarrollo de la enfermedad y no a interrumpir su proceso", en obvia referencia al modelo homeopático. Similares observaciones realizan Zolla et al. (1992) para campesinos mexicanos y Crosnier (1993) y Laplantine (1999) para los franceses. Todas estas prácticas - similares a muchas de las señaladas en este trabajo- son coherentes con la concepción hipocrática de la enfermedad, la cual va mucho más allá del desequilibrio de los valores cálido-fresco y seco-húmedo de los humores, así como su concepción terapéutica excede ampliamente el tan citado principio de oposición. Una de las ideas directrices apreciadas por el pensamiento hipocrático es que toda enfermedad pasa por tres estadios, que es conveniente acompañar: la crudeza, la cocción y la crisis (Sendrail 1983; Laplantine 1999). Así es que la aplicación de un remedio cálido a un trastorno de etiología cálida, tenía la función de "cocer los humores pecantes" y dirigirlos hacia los emuntorios con el fin de arribar a la crisis de la enfermedad (Sendrail 1983) ${ }^{27}$.

Por último, la identificación misma del modelo homeoterápico, la negación de que cualquier remedio fresco se administre contra cualquier

${ }^{27}$ Nótese que esto no sólo coincide con el modelo homeopático, sino que también, con la terapia típicamente sustractiva de los "calores", manifestada por los informantes. 
etiología cálida y viceversa -además de la presencia de otros modelos etiológico-terapéuticos operantes-, determinan que el síndrome cálido-fresco no posea un valor prescriptivo entre los criollos. A similares conclusiones llegan Foster (1994) y Sturzenegger (1999). Sin embargo, también se observó que muchos remedios son definidos - como vimos-, por oposición a la etiología del trastorno contra el cual muestran una sensación de efectividad: "si es bueno para el hígado, por lo tanto es fresco", lo que es bueno para el "chujcho", debe ser algo cálido. Estas observaciones, sumadas al carácter explícito del principio de oposición en el discurso criollo, permiten suponer que las sensaciones de cálido y fresco son culturalmente reconocidas y aplicadas en la prescripción de remedios. Según esto, es válido preguntarse ¿en qué medida posee valor prescriptivo el síndrome cálido-fresco para esta gente? Nuestros informantes dejaron entrever que en el ensayo de nuevos remedios cualquier planta fresca podría ser utilizada contra cualquier enfermedad cálida y viceversa, siempre y cuando dicho remedio haya demostrado su efectividad (en términos sensibles, se entiende). Por ende, el síndrome actuaría como criterio prescriptivo de carácter general en la etnomedicina criolla y no particular. Esta guía aportaría un marco de referencia doble: dentro del vasto conjunto de plantas medicinales con que cuentan los criollos se discriminaría un subconjunto de ellas que pueden ser prescritas para otro subconjunto del también vasto número de trastornos discriminados en función de su oposición o semejanza al carácter fresco-cálido del remedio. Sin embargo, no todos los remedios cálidos curan las enfermedades de etiología fresca - y viceversa-, sino que su especificidad radicaría, en última instancia, en la propiedad intrínseca del remedio. En palabras "lévi-straussianas" la caracterización cálido-fresca de remedios y etiologías - fundada a su vez en datos sensibles- "abriría un derecho a proseguir", un marco de referencia para probar remedios.

Otro aspecto a tener en cuenta es la ontologización de lo cálido y lo fresco evidenciado en el discurso médico criollo. Este proceso se interpreta como derivado de la síncresis producida entre la concepción cristiana e hipocrática de enfermedad. Esta última se habría refigurado y simplificado con el tiempo, de tal manera que las categorías de cálido y fresco dejaron de representarse como valores humorales para ser reinterpretadas en términos ontológicos. En nuestro caso, los modelos alopático ý homeopático que responden a una terapéutica de índole relacional, coexisten con una terapia netamente sustractiva de "una cosa" "de algún lugar", en el sentido cristiano exorcista. La articulación de lo cálido-fresco con otros sistemas simbólicos, especialmente a través de mecanismos de adjunción de potencia en los que intervienen elementos de la simbología 
cristiana, es otra de las expresiones de dicho proceso sincrético. La ambivalencia de las representaciones etiológico-terapéuticas registradas, donde la enfermedad y la curación, de modo paradójico, son concebidas simultáneamente de manera ontológica y relacional, alopática y homeopática, como sostiene Laplantine (1999: 297), no resultan infrecuentes en los análisis médico-antropológicos.

En la terapéutica criolla se evidencian 174 aplicaciones medicinales referidas directa o indirectamente como frescas, en un total de 561 referencias, así como 254 aplicaciones cálidas en 672 referencias totales; esto es, un total de 428 usos medicinales definidos según el síndrome en 1233 referencias totales. Se concluye que la mayor parte de los componentes de la farmacopea, así como la mayor parte de los trastornos y enfermedades identificadas por los criollos se caracteriza en base al síndrome cálido-fresco. Se identificaron modelos etiológico-terapéuticos alopáticos y homeopáticos definidos en base a la caracterización cálido-fresca de remedios y etiologías-terapias. Lo cálido y lo fresco se articula con elementos propios de otros sistemas simbólicos, provenientes tanto de la cultura cristiana como de creencias andinas. Un cierto número de etiologías, formas terapéuticas y elementos de la farmacopea no responden de ninguna manera al síndrome analizado.

A partir del análisis exhaustivo de la farmacopea utilizada y del discurso acerca de la etiología y terapéutica de las enfermedades, y a pesar de no dar cuenta de todas las técnicas terapéuticas ni de todas las enfermedades, se puede concluir que el síndrome cálido-fresco constituye el criterio etiológico-terapéutico central de la medicina popular criolla. Esta lógica implícita evidenciada permite afirmar, con Martínez Hernáez y Comelles (1994: 120), que el folklore médico criollo es mucho más que una colección de curiosidades en la que la variabilidad procede de la arbitrariedad y de la imprecisión de la transmisión oral o de fenómenos de difusión cultural. Por el contrario, representa un sistema claramente articulado en sí mismo y con otros ámbitos de la cultura, de la cual es parte inescindible.

\section{BIBLIOGRAFÍA CITADA}

Álvarez HeydenReich, Laurencia. 1992. "Tipos de curanderos en Hueyapan, Morelos", en R. Campos (comp.), La Antropología Médica en México: tomo 2, 127-138. México: Universidad Autónoma Metropolitana.

ARENAS, PASTOR. 2003. Etnografía y alimentación entre los Toba-ñachilamole'ek y Wichilbuku'tax del Chaco Central (Argentina). San Isidro: Instituto de Botánica Darwinion y P. Arenas. 
BianchetTi, María C. 1989. "Embarazo, parto y puerperio en la Puna y Pre-Puna de Argentina". Cuadernos del GREDES (Grupo de Estudios Socio-Demográficos) 8: 1-42.

CADOGAN, LEÓN. 1957. Apuntes de medicina popular guaireña. Asunción: Imprenta Nacional.

COSMINSKY, SHEILA. 1992. "La atención del parto y la antropología médica", en R. Campos (comp.), La Antropología Médica en México: tomo 2, 139-160. México: Universidad Autónoma Metropolitana.

CROSNIER, CAPUCINE. 1993. "La plante à l'image de l'ordre corporel". Ecologie Humaine 11: 7-21.

CURRIER, RICHARD L. 1966. "The hot-cold syndrome and symbolic balance in Mexican and Spanish-American folk medicine". Etbnology 5: 251-263.

Di Lullo, ORESTES. 1929. La medicina popular de Santiago del Estero. Santiago del Estero: El Liberal.

-. 1983. La razón del folklore. Santiago del Estero: El Liberal.

FOSTER, GEORGE M. 1953. "Relationships between Spanish folk medicine and Spanishamerican folk medicine". Journal of American Folklore 6: 201-217.

—. 1979. "El legado hipocrático latinoamericano: "caliente" y "frío" en la medicina popular contemporánea". Medicina Tradicional 2: 5-21.

- 1994. Hippocrates' Latin American legacy: Humoral medicine in the New World. Langhorne: Gordon \& Breach.

GARCÍA, SilviA P. Y DORA I. JimÉNEZ. 1986. "Natural y postizo: frío y caliente. Sistemas clasificatorios vigentes entre criollos del litoral argentino". Suplemento Antropológico 21: 131-146.

GORDILLO, GASTÓN Y JOSÉ M. LEGUIZAMÓN. 2003. El río y la frontera. Movilizaciones aborígenes, obras públicas y Mercosur en el Pilcomayo. Buenos Aires: Biblos.

HilgerT, NORMA I. 2001. "Plants used in home medicine in the Zenta River basin, Northwest Argentina". Journal of Ethnopharmacology 76: 11-34.

IDOyaGa Molina, ANatilde. 1999a. "El simbolismo de lo cálido y lo frío. Reflexiones sobre el daño, la prevención y la terapia de criollos de San Juan (Argentina)". Mitológicas 14: 7-27.

- 1999b. "La selección y combinación de medicinas entre la población campesina de San Juan (Argentina)". Scripta Ethnologica 21: 7-33.

-. 1999c. "Natural and mythical explanations. Reflections on the taxonomies disease in Northwestern Argentina". Acta Americana 8: 17-32.

- 2000. "La medicina humoral, las nociones de cálido y frío y las prácticas terapéuticas tradicionales en la Argentina", en A. Colatarci (comp.), Folklore Latinoamericano: vol. III, 259-288. Buenos Aires: INSPF-IUNA.

-. 2001. "Lo sagrado en las terapias de las medicinas tradicionales del NOA y Cuyo". Scripta Etbnologica 23: 9-75.

JimÉNeZ DE PuPARELI, DORA. 1984. "Función de la medicina popular en la comunidad entrerriana y su relación con la medicina oficial", en Fundación F.G. Bracht (ed.), Cultura tradicional del área del Paraná medio: 235-253. Buenos Aires: Instituto Nacional de Antropología.

KATZ, ESTHER. 1997. "Baños terapéuticos y postparto entre los indígenas de la Mixteca Alta (México)". Parodiana 10: 153-164.

KUSCHICK, INGRID. 1995. Medicina popular en España. Madrid: Siglo XXI.

LAPLANTINE, FRANÇOIS. 1999. Antropología de la enfermedad. Estudio etnológico de los sistemas de representaciones etiológicas y terapéuticas en la sociedad occidental contemporánea. Buenos Aires: Del Sol. 
LÉvi-Strauss, Claude. 1994. El pensamiento salvaje. México: Fondo de Cultura Económica.

MantegazZA, PaOlo. 1949 [1858-1860]. Cartas médicas sobre la América Meridional. S.M. de Tucumán: Universidad Nacional de Tucumán, publicación n. 535 (Traducción de la edición original italiana).

MARISCOTTI DE GÖRLITZ, ANA MARÍA. 1978. "Pachamama Santa Tierra. Contribución al estudio de la religión autóctona de los Andes Centro-Meridionales". Indiana, Suplemento n. 8 .

MARTÍNEZ HeRNÁEZ, ÁNGEL Y JOSEP M. COMELlES. 1994. "La medicina popular. ¿Los límites culturales del modelo médico?". Revista de Dialectología y Tradiciones Populares 49: 109-136.

MENÉNDEZ, EDUARDO. 1992. "Autoatención y automedicación. Un sistema de transacciones sociales permanentes", en R. Campos (comp.), La Antropología Médica en México: tomo 1, 141-185. México: Universidad Autónoma Metropolitana,

MESSER, ELLEN. 1987. "The hot and cold in Mesoamerican indigenous and hispanicized thought". Social Science \& Medicine 25: 339-346.

PALMA, NÉstor H. 1978. La medicina popular en el Noroeste argentino. Buenos Aires: Huemul.

PEeters, Alice. 1979. "La pocaution c'est maman felicité". Communications 31: 130-144.

QUEIROZ, MARCOS S. 1984. "Hot and cold classification in traditional Iguape medicine". Etbnology 23: 63-72.

Scarpa, Gustavo F. 2000a. Estudio etnobotánico de la subsistencia de los criollos del Chaco Noroccidental argentino. Tesis doctoral, Facultad de Ciencias Exactas y Naturales de la Universidad de Buenos Aires, Buenos Aires.

- 2000b. "Plants employed in traditional veterinary medicine by the Criollos of the Northwestern Argentine Chaco". Darwiniana 38: 253-265.

- 2002. "Plantas empleadas contra trastornos del sistema digestivo en la medicina folk de los Criollos del Chaco Noroccidental argentino". Dominguezia 18(1): 36-50.

- 2004. "Medicinal plants used by the Criollos of Northwestern Argentine Chaco". Journal of Ethnopharmacology 91(1): 115-135.

SENDRAIL, MARCEL. 1983. Historia cultural de la enfermedad. Madrid: Espasa-Calpe.

STURZENEGGER, ODINA. 1985. "Enfermedad mental en un mundo arcaico". Documenta Laboris 5, n. ${ }^{\circ}$ 72. Buenos Aires: Consejo Nacional de Investigaciones Científicas y Técnicas.

-. 1987. "Medecine traditionnelle et pluralisme medical dans une culture creole du Chaco Argentin", Mémoire pour le D.E.A. "Anthropologie: Biologie Humaine et Société”, Universite de Droit, D'Economie et des Sciences D'Aix-Marseille, Marseille.

- 1989. "Maladie et environnement culturel: à propos des "Culture-bound syndromes". Ecologie bumaine 7: 53-62.

-. 1999: Le mauvais œil de la lune. Etbnomédecine créole en Amérique du Sud. París: Karthala.

TORRES, Graciela. 1982. "Curanderismo y brujería en el área de la Selva TucumanoOranense". Documenta Laboris 2, n. 28. Buenos Aires: Consejo Nacional de Investigaciones Científicas y Técnicas.

WALSER, H.H. Y H.M. KOELBING 1971. "Introducción: Conversación con Erwin H. Ackerknecht", en E. H. Ackerknecht, Medicina y Antropología Social. Estudios varios: 9-18. Madrid: Akal.

ZOlla, CARlos et al. 1992. "Medicina tradicional y enfermedad", en R. Campos (comp.), La Antropología Médica en México: tomo 2, 71-104. México: Universidad Autónoma Metropolitana. 